\title{
Efffect of desensitizing agents on the bond strength of dental adhesive systems
}

\author{
Luciene Santana Andreatti ${ }^{1}$, Murilo Baena Lopes ${ }^{1}$, Ricardo Danil Guiraldo ${ }^{1}$, Alvaro Henrique Borges², \\ Maura Cristiane Orçati Dorilêo ${ }^{2}$ and Alcides Gonini Jrr*
}

\author{
* Correspondence: \\ alcides.gonini@gmail.com \\ ${ }^{1}$ University of North Parana, Rua \\ Marselha, 183, Londrina, Paraná CEP \\ 86041-100, Brasil \\ Full list of author information is \\ available at the end of the article
}

\begin{abstract}
The exposure of dentin to the oral environment leads to dentinal sensitivity, the treatment of which exposes the substrate to various substances that can alter its interaction with adhesive restorative materials. The objective of this study was to analyze whether the prior use of desensitizing agents interferes with the bond strength of resin restorative materials. A total of 48 molars were divided into six groups, according to conventional application (CV) of the adhesive systems Scotchbond Multipurpose (SB) and Clearfil SE Bond (CF) and their association with bioglass (BG/Biosilicate ${ }^{\circledR}$ ) or arginine (AR/Sensitive Pro-Relief/TM). Bond strength was assessed by a microshear mechanical test, using a composite resin as restorative material (Filtek Z350 XT). Mechanical testing was performed at a speed of $0.5 \mathrm{~mm} / \mathrm{min}$ in a universal testing machine, and the data were submitted to two-way ANOVA and Tukey's test $(a=0.05)$. The bond strength (MPa) was 17.03 for SBCV; 21.19 for SBAR; 26.24 for SBBG; 21.37 for CFCV; 27.09 for CFAR and 29.51 for CFBG group. A significant increase in bond strength $(p<0.05)$ was observed when Biosilicate ${ }^{\circledR}$ was used prior to the conventional and self-etching adhesive systems. Fracture pattern analysis by means of optical microscopy showed a predominance of mixed type fractures, with the exception of the CFCV group, where adhesive fractures predominated. It is concluded that arginine did not interfere with the bond strength with dentin, while the use of Biosilicate ${ }^{\circledR}$ tended to strengthen the bond between dentin and the adhesive systems used.
\end{abstract}

Keywords: Dentin adhesives; Resin restorative materials; Microshear; Desensitizers; Dentin

\section{Background}

Dentinal hypersensitivity is characterized by pain arising from exposed dentin in response to an external stimulus that can have a thermal, tactile, osmotic or chemical origin, where it is not explained by other forms of dental defect or pathology [1]. It is a relatively common situation in clinical practice and affects areas with gingival recession or enamel loss and can occur naturally with age, but it is typically associated with brushing and periodontal disease [2].

For hypersensitivity to occur, the exposed dentin must have at least two hyperconductive characteristics, open tubules on the dentin surface and that lead to vital pulp [3,4]. In these conditions, sensitivity can be explained by the hydrodynamic theory, suggesting that external stimuli promote the movement of dentinal fluid in the tubules, altering the pressure along the dentin tissue, stimulating nerve fibers and causing pain by

(c) 2014 Andreatti et al.; licensee Springer. This is an Open Access article distributed under the terms of the Creative Commons Attribution License (http://creativecommons.org/licenses/by/4.0), which permits unrestricted use, distribution, and reproduction in any medium, provided the original work is properly credited. 
the slight physical displacement of odontoblasts or pre-dentin nerves [5,6]. Other hypotheses consider that nerve endings or nociceptors located in the dentin could respond directly to external stimuli or that odontoblasts act as receptors, generating nerve impulses when depolarized by chemical or electrical action [2,7].

Based on these hypotheses, the treatment of dentinal hypersensitivity can be accomplished by regulating nerve transmission or by the obliteration of open and exposed dentinal tubules [2,7] through the application of toothpastes with specific active ingredients in their formulations $[2,7]$.

In the selection of substances, potassium salts act on the regulation of nerve transmission through the release of potassium ions in the extracellular medium, which upon reaching a concentration higher than the physiological concentration begin to induce depolarization of nerve cells, making the nerve unable to respond to the excitatory stimuli. Strontium chloride and stannous fluoride act on mechanical occlusion by the deposition and precipitation of compounds in the dentinal tubules, while substances such as arginine and active bioglasses act on the mechanical blockage of the tubules by the formation and deposition of natural minerals [7].

Despite being an aminoacid found in saliva, arginine, when administered in combination with calcium carbonate in the form of a prophylactic paste, potentiates its natural action mechanism, facilitating the sealing of exposed dentinal tubules by depositing material similar to dentin, producing immediate and lasting desensitization [8,9]. Among the active bioglasses, Biosilicate ${ }^{\bullet}$, which by nature is an osteoconductive material, can bind chemically to the dentin surface and obliterate the tubules, preventing the movement of fluid within them and thus eliminating the cause of pain [10]. In this case, chemical bonding occurs by the formation of hydroxycarbonate apatite on the dentin surface, resulting in a longer lasting interaction with dental tissue [10].

Despite not being very soluble in aqueous media and presenting some resistance to acid, both arginine and bioglass, when applied to exposed dentin, may interfere with the bond strength of dentin adhesive systems. Therefore, the objective of this study was to evaluate, using a microshear assay, the bond strength of a nanoparticle resin composite and dentin previously treated with a solution of active bioglass (Biosilicate ${ }^{\circ}$ ) or paste with arginine. Both conventional three-step adhesives and two-step self-etching adhesives were included in the study.

\section{Methods}

After approval of the study by the Research Ethics Committee, forty-eight healthy third molars without fracture lines, caries or malformation were selected. These were cleaned and disinfected in a $0.5 \%$ chloramine solution for seven days $\left(4^{\circ} \mathrm{C}\right)$ and then stored in distilled water $\left(4^{\circ} \mathrm{C}\right)$ until use.

The tooth roots were sectioned at the height of the cementoenamel junction with a diamond disc (Extec 12205, Extec Corp., Enfield, USA) under refrigeration, and the coronal portion was mesiodistally medially split according to the long axis of the tooth. Each coronary section was embedded in a section of a PVC tube with colorless chemically activated acrylic resin (Jet - Artigos Odontológicos Clássico LTDA, Campo Limpo Paulista - São Paulo, Brazil), keeping the exposed enamel surface parallel to the horizontal plane. The surface was abraded with a silicon carbide sandpaper disk (3 M Brazil) coupled 
to a polisher (Arotec Ind. Com. S. A., Rio de Janeiro, Brazil) under constant cooling to expose a dentin surface of medium depth. The teeth were stored in artificial saliva for 24 hours at $37^{\circ} \mathrm{C}$ and randomly divided into 6 groups based on the desensitizing agents and adhesive systems used (Table 1).

As shown in the flowchart (Additional file 1: Table S1), after dentin exposure, two groups received the application of adhesive systems (controls - CV); two groups received the prior application of an arginine-based desensitizing agent (AR) using an impregnated rubber cup for 3 seconds, removing the excess with deionized water and reapplying the agent; and two groups received the prior application of $10 \%$ Biosilicate solution (BG), which was rubbed in two 30 second stages with an interval of 3 minutes. Three transparent cylindrical matrices (Tygon Tube, Norton Performance Plastic Co, Cleveland OH, USA) were then positioned on the dentin surface after hybridization, and filled with composite resin (Filtek Z350 XT - 3 M-ESPE, St Paul, USA), based on the literature [11]. After composite resin polymerization using a halogen light apparatus

Table 1 Materials used and treatment protocol

\begin{tabular}{|c|c|c|c|}
\hline Material & Composition & Protocol & Manufacturer \\
\hline \multirow{7}{*}{$\begin{array}{l}\text { Adper Scotchbond } \\
\text { Multiuse adhesive } \\
\text { system }\end{array}$} & \multirow[t]{3}{*}{ Primer: HEMA, polyalkenoic acid. } & $\begin{array}{l}\text { a) phosphoric } \\
\text { acid (37\%): } 15 \mathrm{sec} \text {. }\end{array}$ & \multirow[t]{7}{*}{$\begin{array}{l}3 \text { M ESPE, } \\
\text { St Paul, USA }\end{array}$} \\
\hline & & b) tap water: $15 \mathrm{sec}$. & \\
\hline & & $\begin{array}{l}\text { c) removal of excess } \\
\text { moisture with paper } \\
\text { towel. }\end{array}$ & \\
\hline & \multirow[t]{4}{*}{ Bond: Bis-GMA, HEMA and amines. } & d) primer & \\
\hline & & $\begin{array}{l}\text { e) air jet: } 5 \mathrm{sec} . \\
\text { (distance } 10 \mathrm{~cm} \text { ) }\end{array}$ & \\
\hline & & f) adhesive & \\
\hline & & $\begin{array}{l}\text { g) photoactivation: } \\
10 \text { seconds. }\end{array}$ & \\
\hline \multirow[t]{5}{*}{$\begin{array}{l}\text { Clearfil SE Bond } \\
\text { adhesive system }\end{array}$} & \multirow{2}{*}{$\begin{array}{l}\text { Primer: MDP, HEMA, camphorquinone, } \\
\text { hydrophilic dimethacrylate, N, N-diethanol } \\
\text { P-toluidine and water. }\end{array}$} & $\begin{array}{l}\text { a) primer: rubbing } \\
\text { for } 20 \mathrm{sec} \text {. }\end{array}$ & \multirow{5}{*}{$\begin{array}{l}\text { Kuraray } \\
\text { Medical Inc, } \\
\text { Tokyo, Japan. }\end{array}$} \\
\hline & & $\begin{array}{l}\text { b) air jet: } 10 \mathrm{sec} . \\
\text { (distance } 10 \mathrm{~cm} \text { ) }\end{array}$ & \\
\hline & \multirow{3}{*}{$\begin{array}{l}\text { Bond: MDP, BIS-GMA, HEMA, hydrophobic } \\
\text { aliphatic dimethacrylate, camphorquinone, } \\
\text { N, N-diethanol-P-toluidine, silanized } \\
\text { colloidal silica. }\end{array}$} & c) adhesive & \\
\hline & & $\begin{array}{l}\text { d) air jet: } 10 \mathrm{sec} \text {. } \\
\text { (distance } 10 \mathrm{~cm} \text { ) }\end{array}$ & \\
\hline & & e) photoactivation: $10 \mathrm{sec}$. & \\
\hline \multirow[t]{3}{*}{$\begin{array}{l}\text { Colgate Sensitive } \\
\text { Pro-Relief Paste }\end{array}$} & \multirow{3}{*}{$\begin{array}{l}\text { Calcium carbonate, hydrated silica, glycerin, } \\
\text { arginine, water, sodium bicarbonate, } \\
\text { fragrance, sodium carboxymethylcellulose, } \\
\text { sodium saccharin, blue } 1(\mathrm{Cl} 42090) \text {. }\end{array}$} & $\begin{array}{l}\text { a) application with } \\
\text { impregnated rubber cup } \\
\text { at low speed for } 3 \text { sec. }\end{array}$ & \multirow[t]{3}{*}{$\begin{array}{l}\text { Palmolive } \\
\text { Company, } \\
\text { New York, USA }\end{array}$} \\
\hline & & $\begin{array}{l}\text { b) rinse with deionized } \\
\text { water }\end{array}$ & \\
\hline & & c) repeat procedure & \\
\hline \multirow[t]{5}{*}{$\begin{array}{l}\text { Aqueous Biosilicate }^{\oplus} \\
\text { solution (10\%) }\end{array}$} & \multirow[t]{5}{*}{$\begin{array}{l}\text { Bioglass mixed with distilled water } \\
\text { (ratio 1:10). }\end{array}$} & $\begin{array}{l}\text { a) application and } \\
\text { rubbing of solution } \\
\text { on dentin for } 30 \mathrm{sec} \text {. }\end{array}$ & \multirow[t]{5}{*}{$\begin{array}{l}\text { Vitrovita, São } \\
\text { Carlos, Brazil. }\end{array}$} \\
\hline & & b) wait: 3 min. & \\
\hline & & c) remove excess: air jet & \\
\hline & & d) repeat procedure & \\
\hline & & $\begin{array}{l}\text { e) rinse with deionized } \\
\text { water }\end{array}$ & \\
\hline
\end{tabular}


(VIP, Bisco, Schaumburg, USA $/ 550 \mathrm{~mW} / \mathrm{cm}^{2}$ for 20 seconds), the matrices were removed and the specimens stored in distilled water at $37^{\circ} \mathrm{C}$ for $24 \mathrm{~h}$. The tests were performed in a universal testing machine (EMIC, DL 2000, São José dos Pinhais, Brazil) in a microshear device at a speed of $0.5 \mathrm{~mm} / \mathrm{min}$. The results (MPa) were submitted to the Kolgomorov-Smirnov normality test followed by two-way ANOVA and Tukey's test $(\alpha=0.05)$.

The surfaces of the specimens were examined under a microscope with 40X magnification to determine the fracture pattern, which was classified as adhesive, cohesive in dentin, cohesive in resin or mixed.

\section{Results}

Regarding the application of adhesive systems in a conventional manner or with prior application of bioglass or arginine, the statistical analysis showed no significant differences $(p>0.05)$ between corresponding groups. However, when comparing the same adhesive system, a significant difference $(\mathrm{p}<0.05)$ was found when Biosilicate ${ }^{\bullet}$ was used. Considering the three-step etch\&rinse adhesive groups, mean shear force was higher for SBBG compared to SBCV and SBAR which were similar to each other. Considering the two-step self-etch adhesive groups, mean shear force was higher for CFBG compared to CFCV and CFAR which were similar to each other (Table 2).

Regarding the fracture pattern, there was a predominance of mixed type in all groups except the CFCV group, where adhesive fracture was the most frequent. Observing the fracture pattern between the groups with conventional use and when bioglass was applied, there was an increase in cohesive fractures in dentin (Figure 1).

\section{Discussion}

The adhesion of restorative materials to dentin is a challenge due to the characteristic moisture of dentin [12]. In addition to this moisture, the presence of components extrinsic to dentin composition can alter the bond between dentin and restorative materials, as occurs between the materials used in the treatment of dentin hypersensitivity and adhesive systems [13-16].

Despite the limitations of in vitro studies, this study aimed to evaluate the effect of two substances indicated in the treatment of dentin hypersensitivity. These substances promote the occlusion of dentinal tubules through chemical reaction, rather than by the mechanical deposition of particles, as proposed by most treatments. For this purpose, a solution of bioglass (Biosilicate ${ }^{\circ}$ ) and an arginine-based paste (Sensitive Pro-Relief) were included in the study.

Table 2 Mean (standard deviation) of bond strength (MPa) in relation to type of adhesive and dentin treatment

\begin{tabular}{llll}
\hline & $\boldsymbol{C V}$ & $\boldsymbol{A R}$ & $\boldsymbol{B} \boldsymbol{G}$ \\
\hline $\mathrm{SB}$ & $17.03( \pm 5.07) \mathrm{aA}$ & $21.19( \pm 7.61) \mathrm{aA}$ & $26.24( \pm 3.39) \mathrm{bA}$ \\
$\mathrm{CF}$ & $21.37( \pm 4.38) \mathrm{aA}$ & $27.09( \pm 6.52) \mathrm{aA}$ & $29.51( \pm 3.50) \mathrm{bA}$
\end{tabular}

Identical lowercase letters in lines represent statistical similarity.

Identical uppercase letters in columns represent statistical similarity.

SB - Adper Scotchbond Multiuse adhesive system; CF - Clearfill SE Bond adhesive system; CV - Conventional adhesive application; AR - Colgate Sensitive Pro-Relief Paste; BG - Aqueous Biosilicate ${ }^{\oplus}$ solution. 


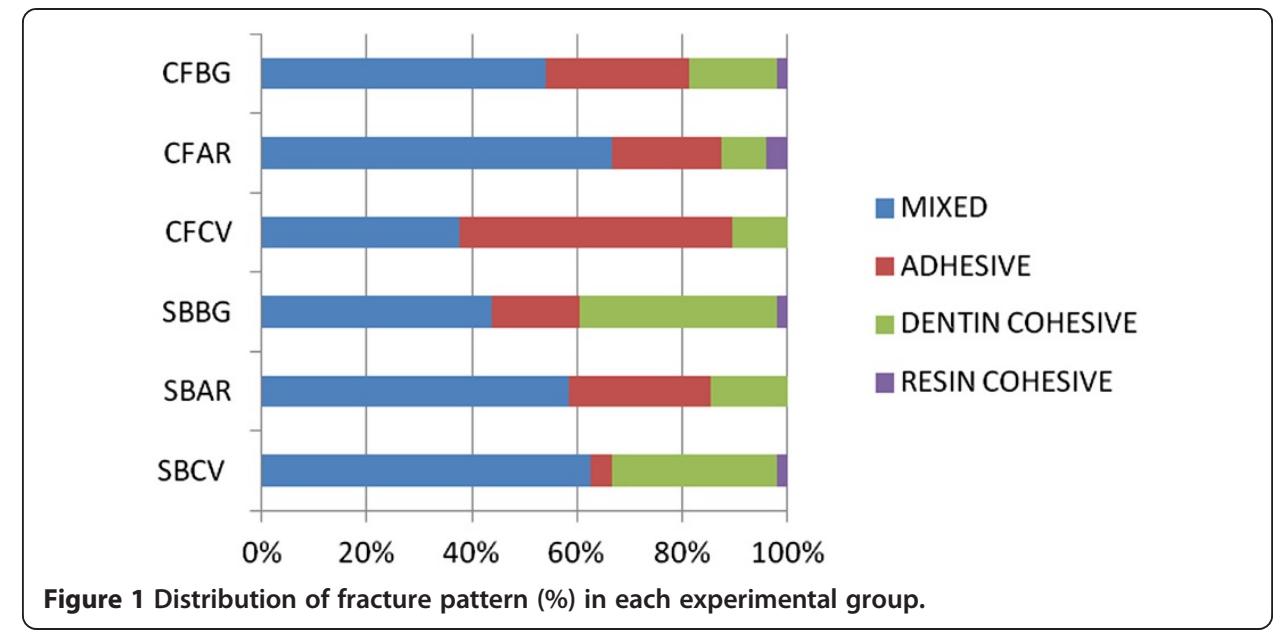

Bioglasses are classified as bioactive materials because they are able to adhere to living tissue, a process established by means of chemical bonds in the interface of the material with the tissue, resulting in the formation of a layer of hydroxycarbonate apatite that is structurally similar to the hydroxyapatite found in bone tissue [17]. Based on the description of the bonding mechanism between bioglass and bone tissue [17] and considering its similarity to dentin, the possibility of adhesion between bioglass and dentin has been demonstrated by means of microscopic and chemical analysis of dentin after its exposure to bioglass [12].

From this perspective, a derivative of the original bioglass (45S6) was indicated for the treatment of dentinal hypersensitivity. It was found that when applied in aqueous solution or incorporated into a dentifrice (7.5\%), pain relief was provided by the rapid formation of a hydroxycarbonate apatite layer on the dentin surface, which was responsible for a decrease in intratubular liquid flow [10].

Biosilicate ${ }^{\circ}$ is among the derivatives of bioglasses with the original formulation $\left(\mathrm{Na}_{2}-\mathrm{CaO}-\mathrm{SiO}_{2}-\mathrm{P}_{2} \mathrm{O}_{5}\right)$, but it also contains $\mathrm{Li}_{2} \mathrm{O}$ and $\mathrm{K}_{2} \mathrm{O}$ [18], and in nanoparticulate form $(0.1$ to $10 \mu \mathrm{m})$ in $10 \%$ solution, it was found to promote the obliteration of dentinal tubules when in contact with dentin for 24 hours [19]. Microscopic and spectrophotometric analysis suggested the formation of an adhesive layer of hydroxyapatite on the dentin surface that is hypothetically responsible for the permanent obliteration of dentinal tubules [20].

Under conditions similar to the present study, it has been observed that rubbing a Biosilicate $e^{\bullet}$ solution ( $0.5 \mathrm{~g}$ in distilled water in a 3:1 ratio) for 10 seconds on bovine dentin prior to the application of a conventional adhesive and a self-etching adhesive improved the bond strength values [20].

Statistically, resistance increased significantly only when Biosilicate ${ }^{\bullet}$ was associated with self-etching adhesive, although it is suggested that this result may have been due to the presence of phosphate methacrylates that favored hydrolytic stability of the system over the period tested [20]. In contrast to expectations, the use of Biosilicate ${ }^{\circ}$ did not reduce conducted light, which could impede penetration of the adhesive system, even with the use of phosphoric acid in the conventional system [20]. In contrast, this study found a significant increase in bond strength resulting from the application of Biosilicate $e^{\circ}$ prior to conventional adhesive and self-etching adhesive. This result suggests that bonding between the substrates was facilitated by the probable 
formation of the hydroxycarbonate apatite layer and not just by the presence of specific adhesive monomers.

It is important to consider that the concentration and time of application adopted for the Biosillicate ${ }^{\bullet}$ solution in this study most likely facilitated the initial reaction with dentin. In addition to the chemical interaction between the substrates through the formation of apatite, the phenomenon may have created a mechanical interaction between the bioglass and dentin particles, increasing adhesion between the substrates [12]. Therefore, there may have been not only a micromechanical interaction between the decalcified dentin substrate and adhesive system but also a micromechanical interaction between Biosilicate particles that had already reacted with the dentin substrate and the polymerized adhesive system, enhancing adherence. Thus, particle size may have been a facilitating aspect for the penetration of Biosilicate ${ }^{\circ}$ into the dentinal tubules, rather than the reverse [20].

In the case of positively charged arginine, it has been found that when incorporated into a dentifrice, it tends to bind to the exposed surface of dentin and negatively charged dentinal tubules, triggering the deposition of calcium phosphate, which adheres to the dentin substrate, obliterating the tubules by forming a protective layer of calcium and phosphate salivary glycoproteins [21]. In this study, assuming that calcium phosphate deposition occurred in the manner described, there was no significant loss in bond strength in the two adhesive systems used, as the strategy of conventional adhesion of the adhesives tested is basically dependent on mechanical imbrications [22-24].

Comparatively, the presence of Biosilicate ${ }^{\circ}$ and arginine did not negatively affect adhesion on the dentin, an opposite situation to other desensitizing agents tested, where the presence of glutaraldehyde [23], fluorine or calcium oxalate [24] and the characteristic acidity of some products decreased the bond strength of the adhesive systems tested [15].

Considering the fracture pattern described in the present study, predominant adhesive fracture in CFCV group could be influenced by the smaller thickness of the hybrid layer [25] when compared to SBCV group, where mixed fracture type was the most frequent. Observing the fracture pattern between the groups with conventional use and when bioglass was applied, there was an increase in cohesive fractures in dentin, probably due to the presence of chemical bonding by the formation of hydroxycarbonate apatite on the dentin surface [10] combined to a micromechanical interaction with tooth tissue improving bonding performance [12].

Although there is no ideal material that permanently occludes dentinal tubules [10], both arginine and Biosilicate ${ }^{\circ}$ are good alternatives in this respect. Despite the limitations of this study, it demonstrated that arginine has no negative effect on the bond strength of adhesive systems tested, corroborating previous results [26-28], while bioglass may improve the action of adhesive systems. Given the benefits that the use of Biosilicate ${ }^{\bullet}$ can provide with regard to the adhesion of adhesive systems, more studies to adjust the concentration and duration of use for effective clinical indication or to analyze it as a potential component of adhesive systems are necessary.

\section{Conclusion}

It is concluded that arginine did not interfere with the bond strength with dentin, while the use of Biosilicate ${ }^{\bullet}$ tended to strengthen the bond between dentin and the adhesive systems used. 


\section{Additional file}

Additional file 1: Table S1. Group classification according to adhesive type and dentin substrate treatment.

\section{Competing interests}

The authors declare that they have no competing interests.

\section{Authors' contributions}

LSA participated in performing the experiments and writing of the manuscript. AHB and MCOD contributed to the writing of the manuscript. RDG performed the statistical analysis. AGJ and MBL conceived of the study, participating in its design and coordination, helping to drafting the manuscript. All the authors have read and approved the final manuscript.

\section{Author details}

${ }^{1}$ University of North Parana, Rua Marselha, 183, Londrina, Paraná CEP 86041-100, Brasil. ${ }^{2}$ Cuiabá University, Avenida Manoel José de Arruda 3.100, Cuiabá, Mato Grosso CEP 78065-900, Brasil.

Received: 4 November 2014 Accepted: 26 November 2014

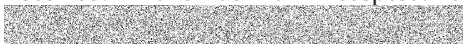

\section{References}

1. Fu Y, Li X, Que K, Wang M, Hu D, Mateo LR, DeVizio W, Zhang YP (2010) Instant dentinal hypersensitivity relief of a new desensitizing dentifrice containing 8.0\% arginine, a high cleaning calcium carbonate system and 1450 ppm fluoride: a 3-day clinical study in Chengdu, China. Am J Dent 23:20A-27A

2. Lavender S, Petrou I, Heu R, Stranick M, Cummins D, Kilpatrick-Liverman L, Sullivan RJ, Santarpia P III (2010) Mode of action studies on a new desensitizing dentifrice, containing the Pro-Argin technology, with a gentle whitening benefit. Am J Dent 23:14A-19A

3. Addy M (2002) Dentine Hypersensitivity: new perspectives on an old problem. Int Dent J 52:367-375

4. Dababneh $\mathrm{RH}$, Khouri AT, Addy M (1999) Dentine hypersensitivity - an enigma? A review of terminology, epidemiology, mechanisms, a etiology and management. Br Dent J 187:606-611

5. Brännström $M$, Aström A (1964) A study on the mechanism of pain elicited from the dentin. J Dent Res 43:619-625

6. Brännström M, Aström A (1972) The hydrodynamics of the dentine; its possible relationship to dentinal pain. Int Dent J 22:219-227

7. Cummins D (2010) Recent advances in dentinal hypersensitivity: clinically proven treatments for instant and lasting sensitivity relief. Am J Dent 23:3A-13A

8. Wolff MS, Kaufman H, Kleinberg I (2002) Dentinal hypersensitivity following scaling and root planning (SRP) and dental prophylaxis. J Dent Res 80:191

9. Schiff T, Delgado E, Zhang YP, Cummins D, DeVizio W, Mateo LR (2009) Clinical evaluation of the efficacy of an in-office desensitizing paste containing $8.0 \%$ arginine and calcium carbonate in providing instant and lasting relief of dentinal hypersensitivity. Am J Dent 22:8A-15A

10. Gillam DG, Tang JY, Mordan NJ, Newman HN (2002) The effects of a novel Bioglass dentifrice on dentine sensitivity: a scanning electron microscopy. J Oral Rehabil 29:305-313

11. Shimada Y, Kikushima D, Tagami J (2002) Micro-shear bond strength of resin-bonding systems to cervical enamel Am J Dent 15:373-377

12. Efflandt SE, Magne P, Douglas LF, Francis LF (2002) Interaction between bioactive glasses and human dentin. Mater Sci 13:557-565

13. Saraç D, Külünk S, Saraç YS, Karakas O (2009) Effect of fluoride-containing desensitizing agents on the bond strength of resin-based cements to dentin. J Appl Oral Sci 17:495-500

14. Lehmann N, Degrange M (2005) Effect of four dentin desensitizer on the shear bond strength of three bonding systems. Eur Cell Mater 9:52-53

15. Yiu CK, King NM, Suh BI, Sharp LJ, Carvalho RM, Pashley DH, Tay FR (2005) Incompatibility of oxalate desensitizers with acidic, fluoride-containing total-etch adhesives. J Dent Res 84:730-735

16. Awang RAR, Masudi SM, Mohd Nor WZW (2007) Effect of desensitizing agent on shear bond strength of an adhesive system. Arch Orofac Sci 2:32-35

17. Hench LL (2006) The story of bioglass. J Mater Sci Mater Med 17:967-978

18. Renno ACM, Bossini PS, Crovace MC, Rodrigues ACM, Zanotto ED, Parizotto NA (2013) Characterization and in vivo biological performance of biosilicate. Biomed Res Int ID:141427

19. Tirapelli C, Panzeri H, Soares RG, Peitl O, Zanotto ED (2010) A novel bioactive glass-ceramic for treating dentinal hypersensitivity. Braz Oral Res 24:381-387

20. Pires-de-Souza FCP, Marco FF, Casemiro LA, Panzeri H (2007) Desensitizing bioactive agents improves bond strength of indirect resin-cemented restorations: preliminary results. J Appl Oral Sci 15:120-126

21. Sensistat KI (2002) A new saliva-based composition for simple and effective treatment of dentinal sensitivity pain. Dent Today 21:42-47

22. Nakabayashi N, Kojima K, Masuhara E (1982) The promotion of adhesion by the infiltration of monomers into tooth substrates. J Biomed Mater Res 16:265-273

23. Pashley DH, Tay FR (2001) Aggressiveness of contemporary self-etching adhesives. Part II: etching effects on unground enamel. Dent Mater 17:430-444

24. Tay FR, Pashley DH (2001) Aggressiveness of contemporary self-etching systems. I: depth of penetration beyond dentin smear layers. Dent Mater 17:296-308 
25. De Munck J, Van Meerbeek B, Inoue S, Vargas M, Yoshida Y, Armstrong S, Lambrechts P, Vanherle G (2003) Micro-tensile bond strength of one- and two-step self-etch adhesives to bur-cut enamel and dentin. Am J Dent 16:414-420

26. Canares G, Salgado T, Pines MS, Wolff MS (2012) Effect of an $8.0 \%$ arginine and calcium carbonate desensitizing toothpaste on shear dentin bond strength. J Clin Dent 23:68-70

27. Wang Y, Liu S, Pei D, Du X, Ouyang X, Huang C (2012) Effect of an $8.0 \%$ arginine and calcium carbonate in-office desensitizing paste on the microtensile bond strength os self-etching dental adhesives to human dentin. Am J Dent 25:281-286

28. Yang H, Pei D, Liu S, wang Y, Zhou L, Deng D, Huang C (2013) Effect of a functional desensitizing paste containing $8 \%$ arginine and calcium carbonate on the microtensile bond strength of etch-and-rinse adhesives to human dentin. Am J Dent 26:137-142

doi:10.1186/s40563-014-0024-y

Cite this article as: Andreatti et al: Efffect of desensitizing agents on the bond strength of dental adhesive systems. Applied Adhesion Science 2014 2:24.

Submit your manuscript to a SpringerOpen ${ }^{\circ}$ journal and benefit from:

- Convenient online submission

- Rigorous peer review

- Immediate publication on acceptance

- Open access: articles freely available online

- High visibility within the field

- Retaining the copyright to your article 